\title{
A RARE CASE OF NEGLECTED UNREDUCED POSTERIOR DISLOCATION OF HIP MANAGED WITH TOTAL HIP ARTHROPLASTY- A CASE REPORT
}

\author{
P. V. Pugalenthi ${ }^{1}$, S. Ramanathan'2, N. Thanappan ${ }^{3}$, M. Vidhya Sagar 4
}

${ }_{1}^{1}$ Professor, Department of Orthopaedics, Madurai Medical College, Madurai.

${ }^{2}$ Assistant Professor, Department of Orthopaedics, Madurai Medical College, Madurai.

${ }^{3}$ Associate Professor, Department of Orthopaedics, Madurai Medical College, Madurai.

${ }_{4}^{4}$ Postgraduate Student, Department of Orthopaedics and Traumatology, Madurai Medical College, Madurai.

\section{ABSTRACT}

\section{BACKGROUND}

Treatment of old, neglected, unreduced dislocation of hip is usually associated with lot of difficulties and requires complex reconstructive procedures.[1,2] Various options available are open reduction, ${ }^{[3]}$ trochanteric osteotomies, ${ }^{[4]}$ arthrodesis ${ }^{[5,6]}$ and arthroplasty.[1,7]

\section{CASE REPORT}

Here we have a case of 45-year-old male with a 14-year-old unreduced neglected posterior dislocation of Lt. hip with $7 \mathrm{~cm}$ shortening and muscle wasting with Trendelenburg test, telescopy test positive, weakness in active abduction and flexion deformity. For which patient is initially treated with skeletal traction to stretch the muscles and soft tissues. Then staged procedure of release of contracted muscles and soft tissues in first sitting followed by skeletal traction for 3 weeks. Then total hip arthroplasty of Lt. Hip was done.

\section{DISCUSSION}

Post-operatively, patient was followed up and he obtained pain free, functional and stable range of movements to do all his activities of daily living without any hindrance. Total hip arthroplasty has the upper hand in treating very old, unreduced and neglected posterior dislocation hip (like in this case- 14 years old dislocation!); because as per literature open reduction is not possible for dislocations > 3 months, as it finally leads to AVN and a painful and stiff joint. Also other procedures like subtrochanteric osteotomies lead to limping and limitation of range of the hip for most of the authors and arthrodesis leads to stable but fixed and immobile hip.

\section{CONCLUSION}

Total Hip Arthroplasty is a safe and acceptable procedure for very old, unreduced and neglected dislocation of hip providing a stable, pain free and mobile hip.

\section{KEYWORDS}

Unreduced Neglected Hip Dislocation, Primary Hip Arthroplasty, Open Reduction of Hip Joint.

HOW TO CITE THIS ARTICLE: Pugalenthi PV, Ramanathan S, Thanappan N, et al. A rare case of neglected unreduced posterior dislocation of hip managed with total hip arthroplasty- a case report. J. Evolution Med. Dent. Sci. 2017;6(23):1953-1957, DOI: 10.14260/Jemds/2017/428

\section{BACKGROUND}

Neglected posterior dislocation of the hip is not uncommon. The management of these cases is a difficult task because of adhesions, soft tissue contractures, acetabular cavity is filled up with fibrofatty tissue and presence of myositis ossificans. Most of the time, it requires complex reconstructive procedures. Watson Jones (1956) encountered difficulties in open reduction, which lead to degenerative arthritis and finally joint fusion was performed.[3] Open reduction of old dislocations of the hip are usually not advised,[8] because of its associated haemorrhage and shock[9],[10] (Amstrong 1948, Gupta and Chaturvedi 1963) and finally results in painful and stiff joint[5],[6] (Roaf 1956, Gupta and Chaturvedi 1963,

Financial or Other, Competing Interest: None.

Submission 06-02-2017, Peer Review 08-03-2017,

Acceptance 14-03-2017, Published 20-03-2017.

Corresponding Author:

Dr. P. V. Pugalenthi, M.S.Ortho. D.Ortho.

Professor,

No 45, West Cross

Shanmugapuram, Karupayurani (Po) , Madurai-20

E-mail: drpugalortho@gmail.com

DOI: $10.14260 /$ jemds $/ 2017 / 428$
Agarwal and Singh 1967). Other options like trochanteric and subtrochanteric osteotomy, though few workers got satisfactory results,[4] most other researchers have not obtained satisfactory results and it was also associated with limp and limitations of movements of the hip joint after the osteotomy procedures. The other treatment options available are excision arthroplasty, arthrodesis ${ }^{[5,6]}$ and replacement arthroplasty.[1,7] Here, we discuss a case of 14 years old! neglected posterior dislocation of Lt. hip in a 45-year-old male with avascular necrosis of femoral head and completely devoid of articular cartilage treated with Total Hip Replacement Arthroplasty.

\section{CASE HISTORY}

A 45-year-old male, lorry driver by occupation had sustained RTA 14 years back and sustained injury to his Lt. hip. He was treated in a nearby native treatment centre by traditional bone setter in the form of egg plaster casts for 3 months. Patient was bedridden and did not go for work for a year. Patient had complaints of shortening of Lt. lower limb, limping, difficulty in activities of daily living like difficulty in squatting and not able to sit with crossed legs for the past 14 years. Patient also has complaints of dull aching pain over his 
Lt. hip for 14 years, which was aggravated on exertion and relieved on rest and analgesics.

\section{CLINICAL EXAMINATION}

On Inspection: Patient had short limb gait and Trendelenburg gait. There was exaggerated lumbar lordosis, flexion deformity of Lt. hip, shortening of Lt. lower limb, thigh and gluteal muscle wasting Lt. side. A mass was visible over posterior aspect in gluteal region, which moves on moving Lt. lower limb suggesting posteriorly dislocated femoral head.

On palpation: Femoral head palpated posteriorly in gluteal region and it moves on moving Lt. lower limb, femoral pulse feeble felt on Lt. side compared to Rt. side (vascular sign of Narath +ve), patient had weakness in active abduction, but all passive range of motions in coronal plane are exaggerated in Lt. hip joint with flexion deformity of 30 degrees.

On measurements: Shortening of $10 \mathrm{cms}$ in Lt. Lower limb, thigh and gluteal muscle wasting were present.

Telescopy test was positive, vascular sign of Narath was positive and Trendelenburg test was positive on Lt. side.

Gait: Short limb and Trendelenburg gait was present.

On x-ray, AP view of pelvis with both hips and left hip with thigh:

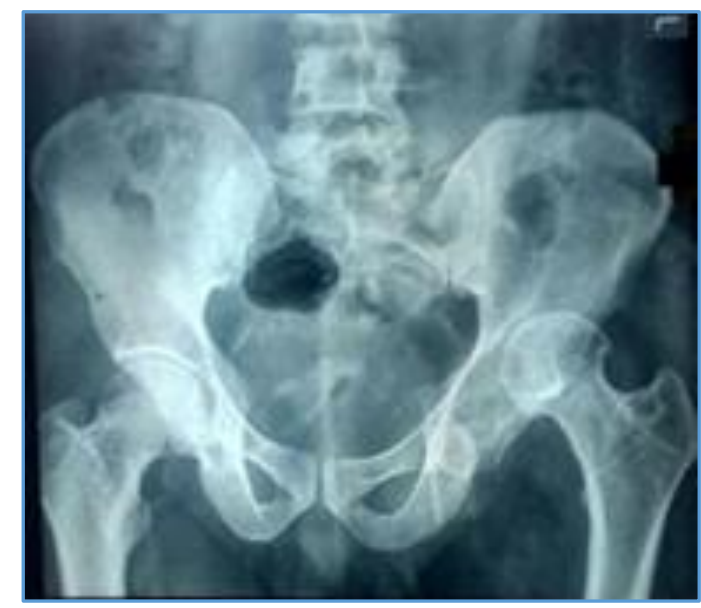

Figure 1

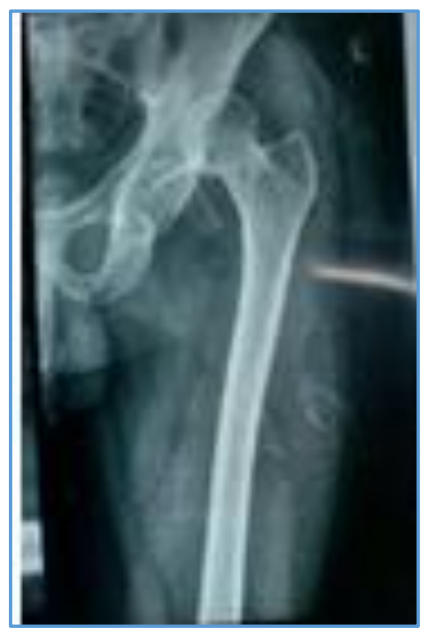

Figure 2

Shows posteriorly dislocated femoral head with areas of patchy sclerosis in femoral head, shallow and irregular acetabulum (Fig. 1 and 2).
On 3D reconstructed computed tomography (3D - CT) and Magnetic Resonance Imaging (MRI):
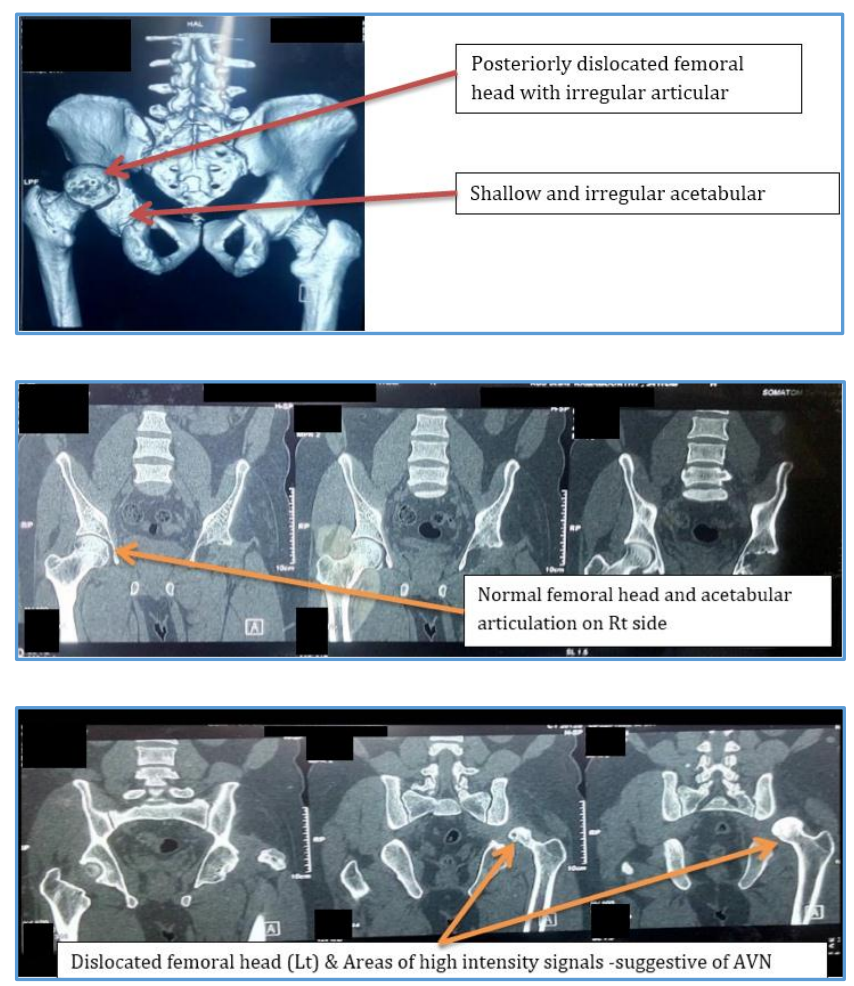

Patient was initially put on skeletal traction (Fig. 2a, b) for 3 weeks (Lower femoral skeletal pin traction with abduction) of about $7 \mathrm{Kgs}$ and serially weights were increased weekly up to a maximum of $10 \mathrm{Kgs}$ and amount of reduction was monitored with serial x-rays every week (Fig. 3, 4, 5).

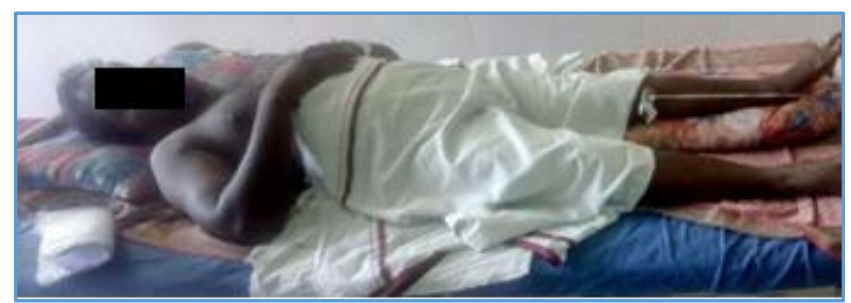

Figure 2a

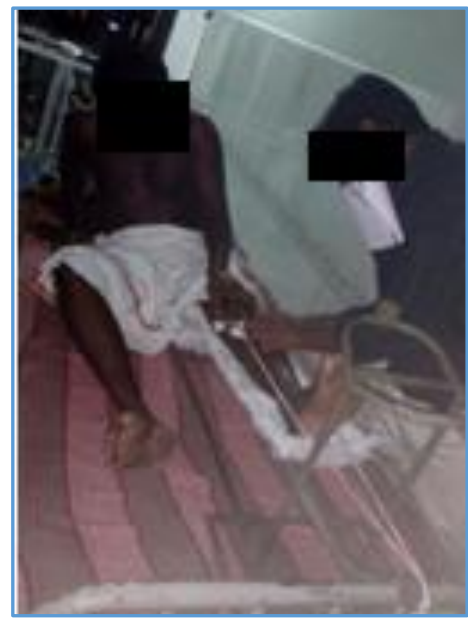

Figure $2 b$ 


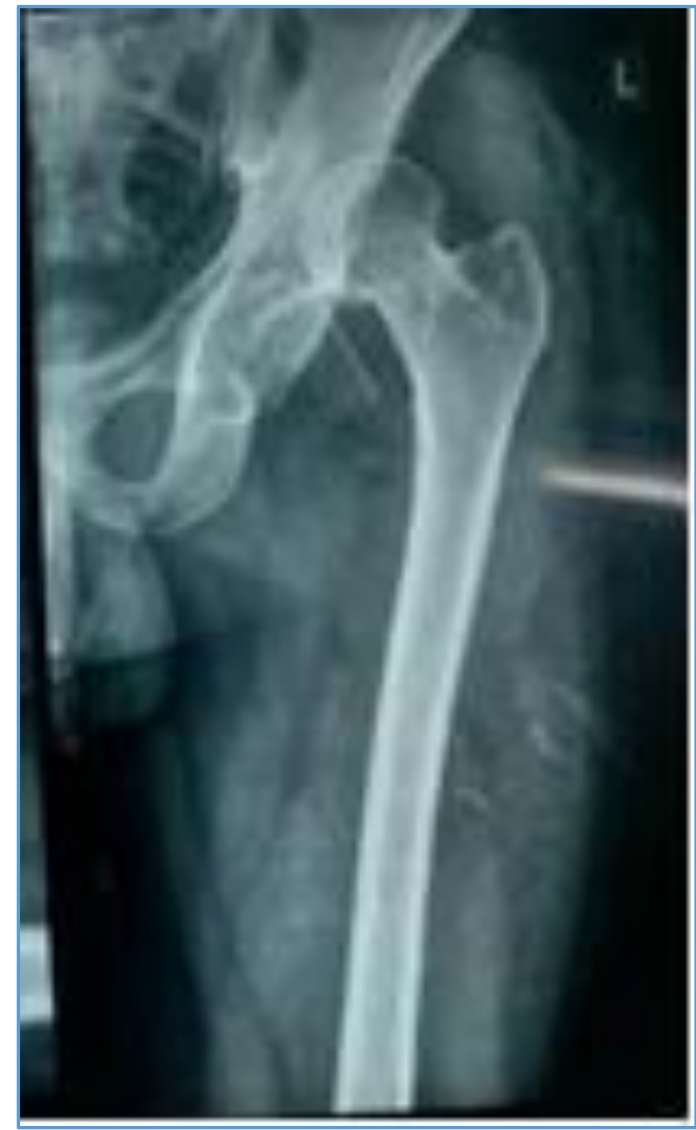

Figure 3 (Week 1)

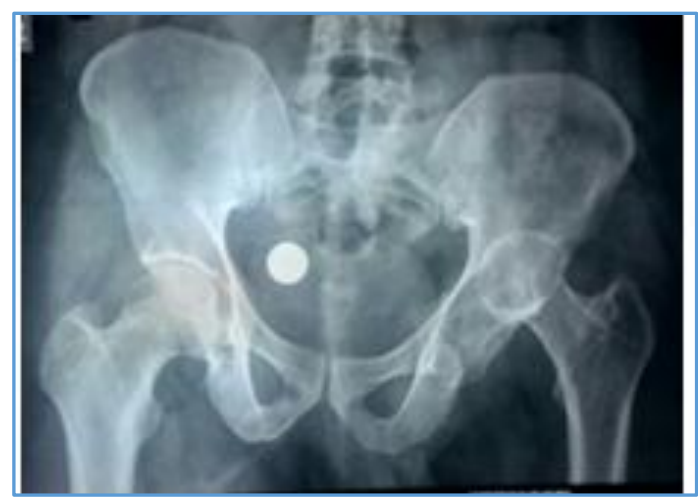

Figure 4 (Week 2)

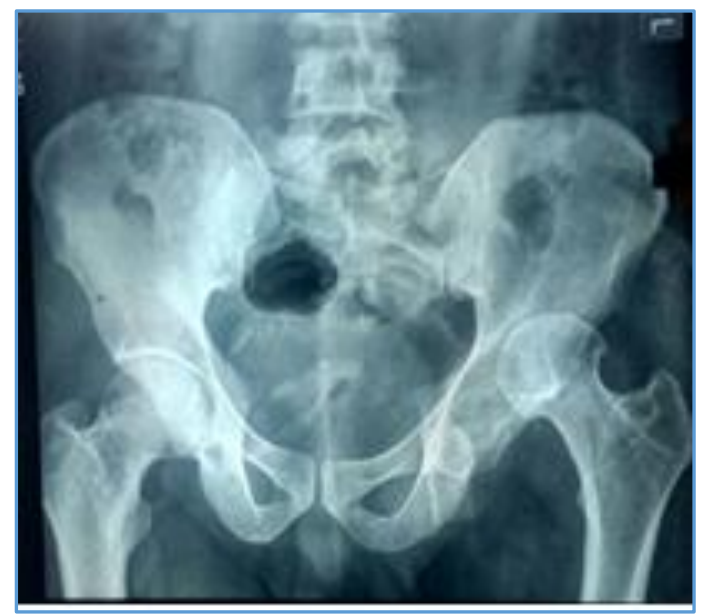

After 3 weeks on traction in the form of lower femoral skeletal pin traction staged procedure of soft tissue release in first sitting and total hip arthroplasty as a second staged procedure were done.

\section{SURGICAL PROCEDURE}

Stage 1 (Soft Tissue Release)

By Southern Moore's postero-lateral approach to Lt. Hip. Femoral head visualised and soft tissue, which were contracted and hindering reduction were released (Taking care and preserving sciatic nerve), mainly iliopsoas (Fig. 6) and by not disturbing the attachments of greater trochanter to preserve abductor mechanism. Femoral head (Fig. 7) was completely devoid of articular cartilage and was irregular.

Patient was put on skeletal traction for 3 weeks following the Stage 1 soft tissue release procedure. To stretch the muscles and soft tissues.
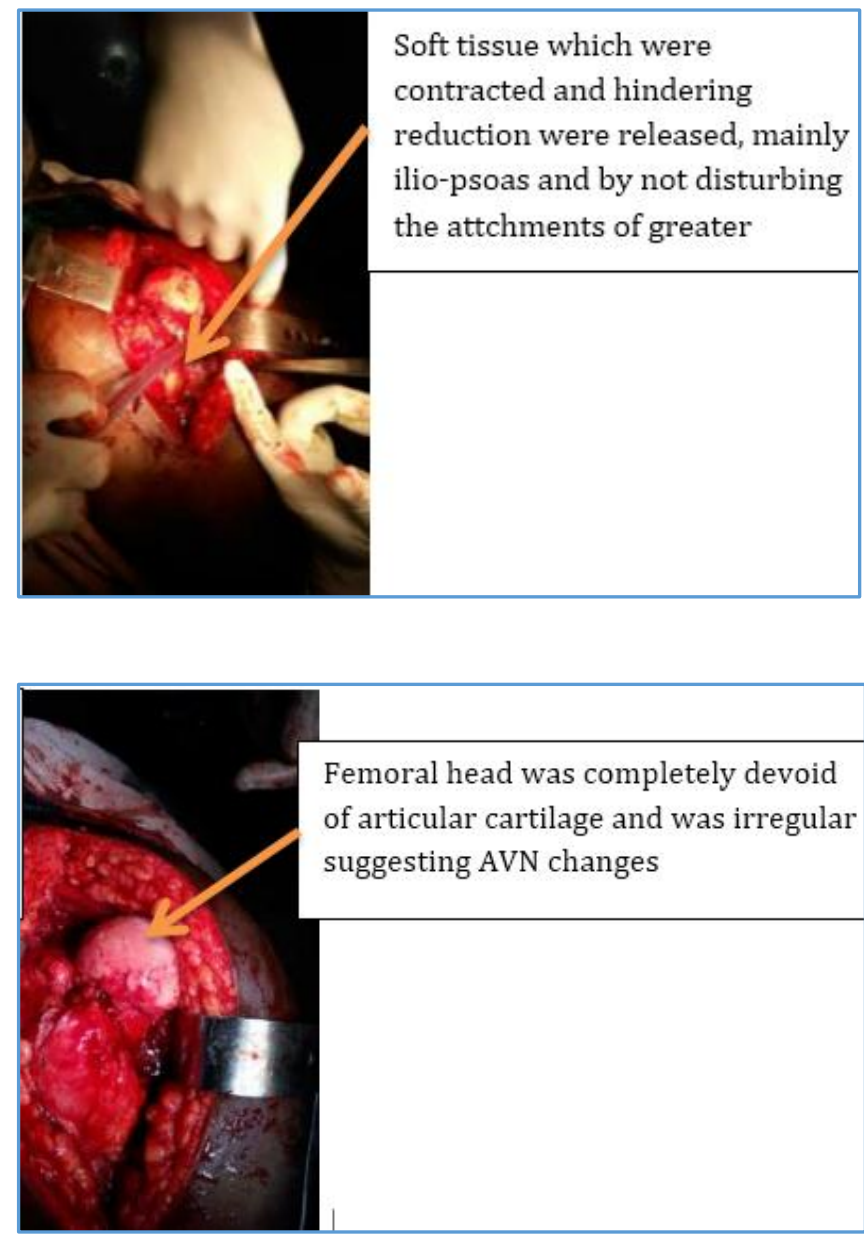

Post-op x-ray after soft tissue release and after 3 weeks of skeletal traction.

Figure 5 (Week 3) 


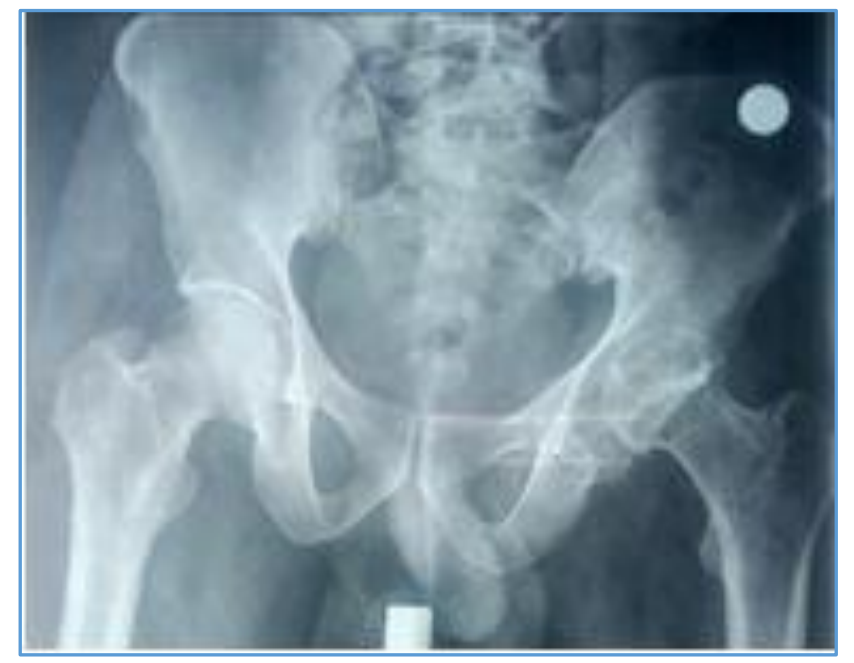

\section{Stage 2 (Total Hip Arthroplasty)}

Under strict aseptic precautions, under spinal anaesthesia, patient in Rt. lateral position by posterior KocherLangenbeck approach to left hip, dislocated femoral head visualised. Then using saw, femoral head along with some portion of neck were osteotomised and removed. Acetabulum was very difficult to visualise, as it was extensively filled with fibrofatty tissue. By tracing the TAL - Transverse Acetabular Ligament, which is the lighthouse for finding the acetabulum and by clearing the fibrofatty tissues acetabulum was located. Then serial reaming of acetabular cavity done. Acetabular margins were prepared by nibbling irregular margins. Then appropriate size acetabular shell and liner were placed. After that femur was prepared by preparing neck and reaming of proximal femur. Then appropriate size femoral stem with appropriate size head was inserted after trial reduction, then Lt. hip joint reduced. It was found to be very stable in all range of movements, even on full adduction and flexion. Capsule was meticulously repaired. Short external rotators were repaired and sutured. Wound washed, closed in layers after keeping suction drain.
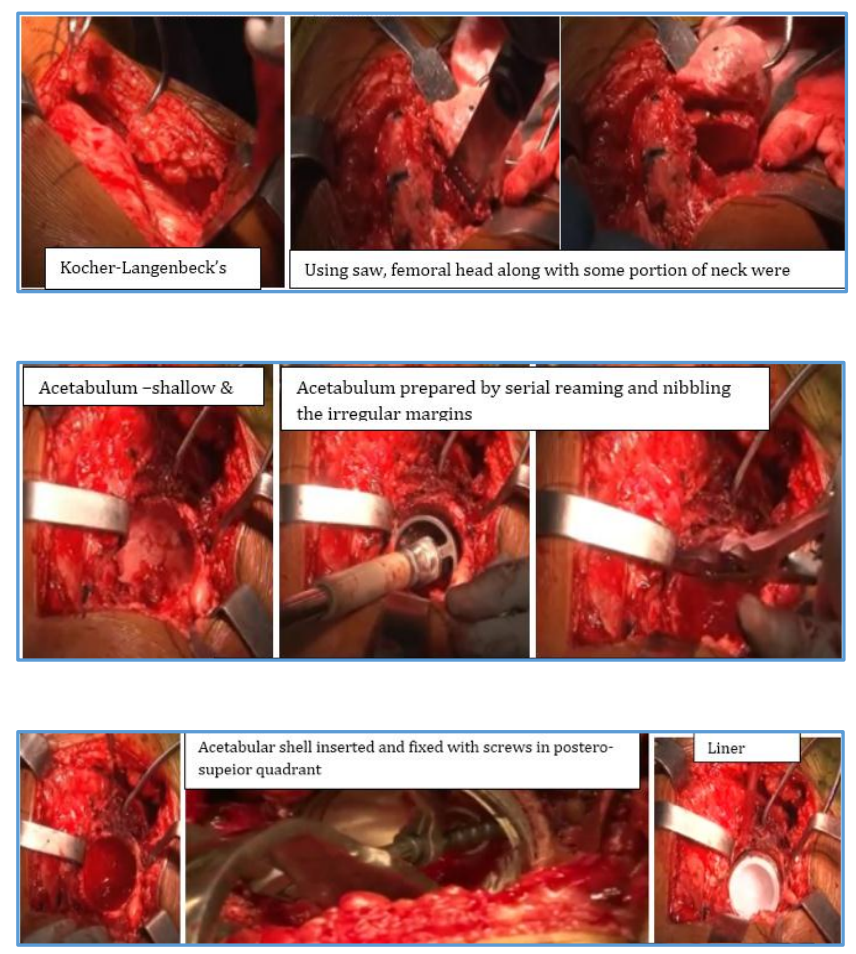

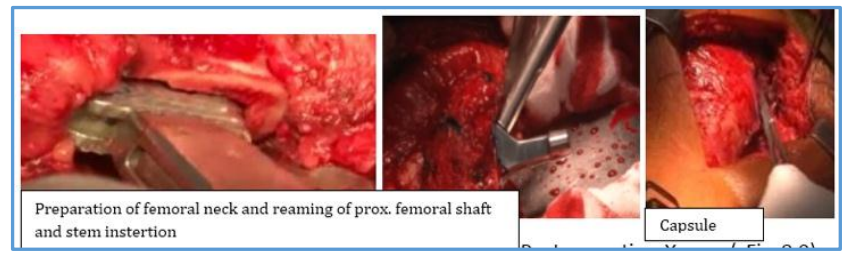

Post-operatively, patient was treated with IV antibiotics. Post-operative x-rays (Fig. 8, 9) were taken. Regular wound dressing made and suture removal was done on POD 12. For 3 weeks post-op, patient was put on traction and was discharged. Patient was on non-weight bearing for 6 weeks post-op and as advised physiotherapy flexion exercises of hip, quadriceps strengthening exercises and guarded weight bearing was started after 6 weeks.

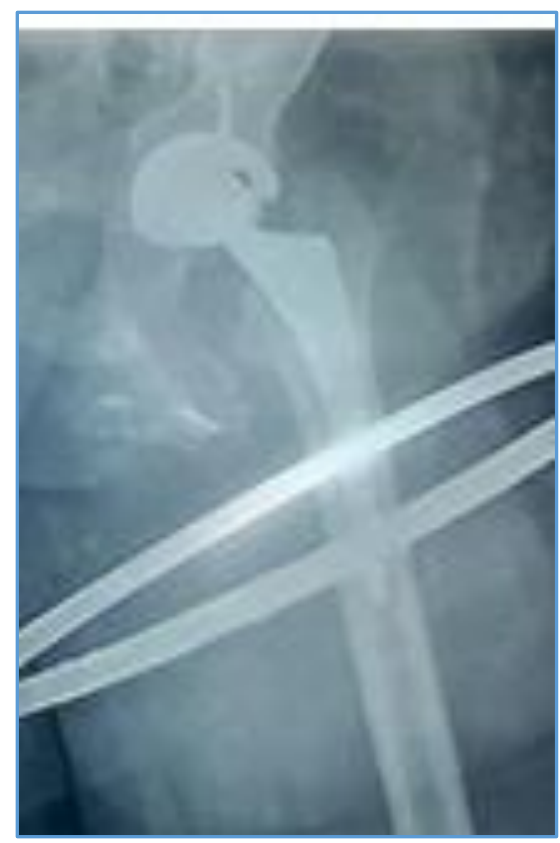

Figure 8

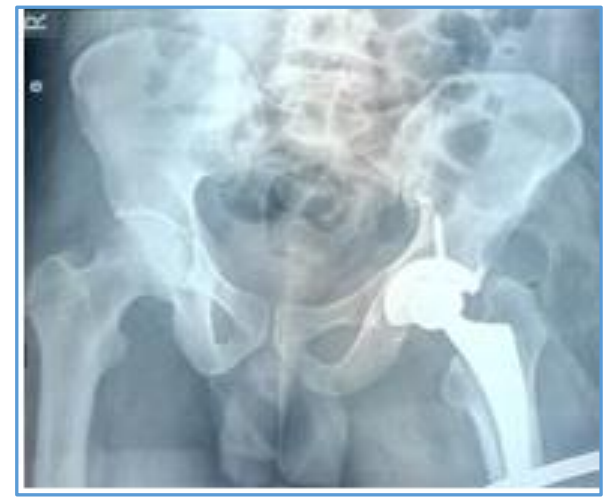

\section{FOLLOWUP}

Patient was asked to come for regular followup every month. Range of movements were assessed. Patient had active flexion of $90 \mathrm{deg}$, abduction of $20 \mathrm{deg}$, adduction of $20 \mathrm{deg}$ and rotations of $20 \mathrm{deg}$ each. Thus, he obtained pain free, functional and stable range of movements to do all his activities of daily living without any hindrance and he was allowed to full weight bearing in Lt. lower limb at the end of two months. At the end of $3^{\text {rd }}$ month, post-op patient was able to return to his job (lorry driving). 


\section{Followup x-rays after 6 months Clinical Picture}
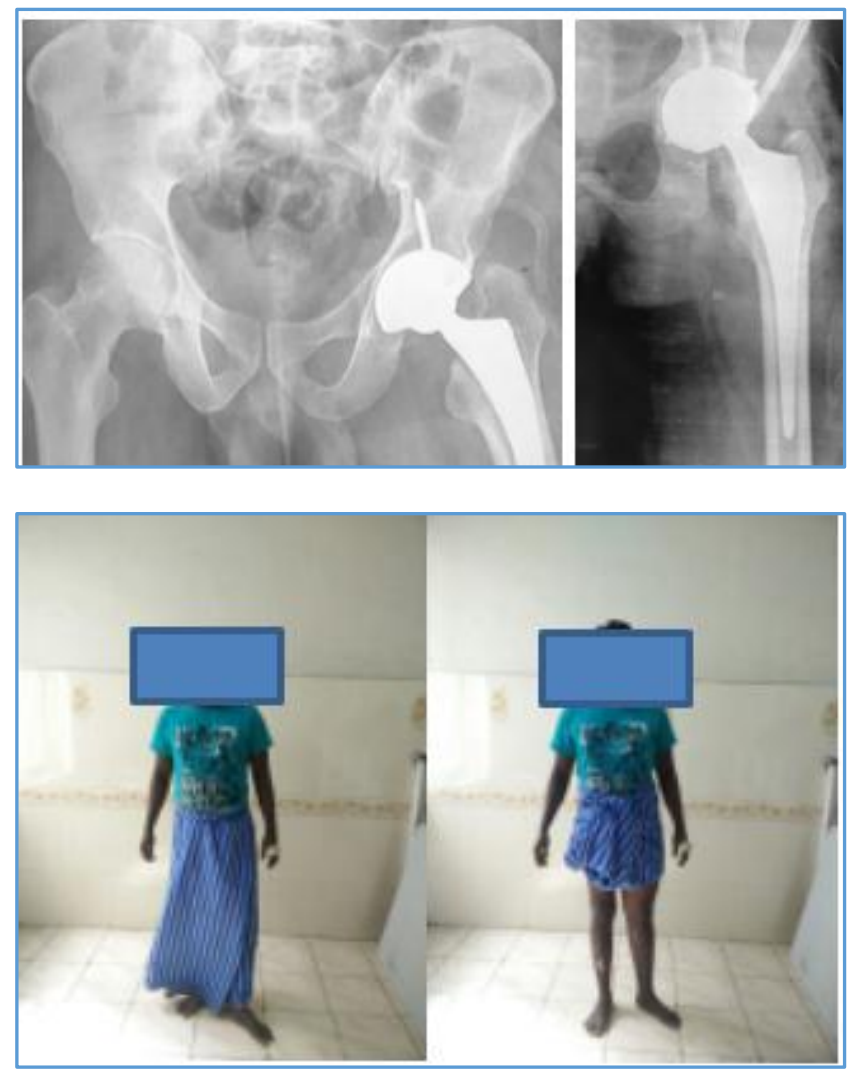

\section{DISCUSSION}

Neglected traumatic dislocation of the hip is not uncommon in developing countries like India, where Road traffic accidents are more common and practice of traditional bone setters are also common. It has been well documented that delayed open reduction of dislocations > 3 months old increases the risk of avascular necrosis and post-traumatic arthritis (Stewart and Milford 1954, Brav 1962, Epstein 1973), it is generally conceded that the end result of posterior dislocation is dependent on the age of the patient, type of dislocation and severity of initial trauma (Funk 1962: Epstein 1973).

The incidence of avascular necrosis varies from 6 percent to over 40 percent in Western literature (Stewart and Milford 1954). Brav (1962) reviewed 262 dislocations and found a relationship between the time of dislocation and the incidence of avascular necrosis. He observed that they were directly proportional. Open reduction is not at all possible in very late neglected posterior dislocation hip. Primary hip arthroplasty has the upper hand in treating very old unreduced and neglected posterior dislocation hip (like in this case- 14 years old dislocation!), because as per literature open reduction is not possible for dislocations $>3$ months, as it finally leads to AVN and a painful and stiff joint. Also, other procedures like subtrochanteric osteotomies lead to limping and limitation of range of the hip for most of the authors and arthrodesis leads to stable but fixed and immobile hip.

\section{CONCLUSION}

Primary Hip Arthroplasty is a safe, definitive and acceptable procedure for very old, unreduced and neglected dislocation of hip providing a stable, pain free and mobile hip joint!!!

\section{REFERENCES}

[1] Andreylotov, Ivanov V, NedelchoTzachev, et al. Primary total hip replacement after neglected dislocation. J Bone Joint Surgery Br 2012;94-B no. SUPP XXXVII 291.

[2] Sathappan SS, Strauss EJ, Ginat D, et al. Surgical challenges in complex primary total hip arthroplasty. Am J Orthop (Belle Mead NJ) 2007;36(10):534-41.

[3] Watson-Jones R. Fractures and joint injuries. Vol II. $4^{\text {th }}$ edn. Edinburgh and London: E \& S Livingstone Ltd., 1956:674-6.

[4] Aggarwal ND, Singh H. Unreduced anterior dislocation of the hip. Journal of Bone and Joint Surgery 1967;49B:288-2.

[5] Roaf R. The natural history of deformities as seen in Northern India. Annals of Royal College of Surgeons of England 1956;18(4):211-27.

[6] Funk F, James JR. Traumatic dislocation of hip in children. Factors influencing prognosis and treatment. Journal of Bone and Joint Surgery 1962;44(6):113545.

[7] Azar FM, Beaty JH, Canale ST. Campbell's operative orthopaedics. Vol 1.12 $12^{\text {th }}$ edn. 2016:178-9.

[8] Amstrong JR. Traumatic dislocation of the hip joint: review of 101 dislocations. Journal of Bone \& Joint Surgery Br 1948;30B(3):430-45.

[9] Gupta AK, Chaturvedi SN. Displacement Osteotomy in cases of old un-reduced ptraumatic dislocation of hip in adults. Indian Journal of Surgery 1963;25:650.

[10] Chaturvedi SN, Gupta AK. Traumatic dislocation of hip in children. Indian Journal of Surgery 1970;32:28. 